Maria $V$. Rygalova, Ph. D. in History

Altai State Institute of Culture (Barnaul, Russia) mariya_rygalova@mail.ru

\title{
FEATURES OF CONTENT AND EXPLOITATION OF GEOGRAPHIC INFORMATION SYSTEM “MUSEUM NETWORK OF ALTAI KRAI" (ALTAI KRAI, RUSSIA)
}

\author{
The reported study was funded by Russian Fund of Basic Research \\ according to the research project no. 18-39-00112
}

\begin{abstract}
The article outlines key results of a two-year (2018-2020) project supported by Russian Fund of Basic Research (Moscow, Russia), aimed at creation of open geographical information system (web-GIS) that reflects key characteristics of institutions included in the museum network of Altai Krai (Russia). The author of the article (head of the project) express her own view on synthesis of the newest GIS-technologies, multimedia system, and technologies of Internet-mapping that will open a brand new stage in practice of visualizing data converted into subject maps and web-GIS free for simple Internet users. Widening the Internet audience who can get an access to detailed data on museum network of Altai Krai within the frame of the project will stimulate the growth of research activities in museology, will give a boost to touristic interest to reach collections of Altai Museums, will join a number of sources that meet the professional information needs of museum Russian community.
\end{abstract}

Keywords: a museum, museum network, Altai Krai, geographical information system (GIS), GIStechnology, mapping, web-GIS.

УДК 655.262.2.0.038:910.4(571.1)

DOI: $10.32340 / 2414-9101-2020-4-66-72$

Н. В. Воробьёва

Алтайская краевая универсальная научная библиотека им. В. Я. Шишкова (Барнаул, Россия) ork_akunb@mail.ru

\section{КАМЕННАЯ ПАЛИТРА АЛТАЯ В ХУДОЖЕСТВЕННОЙ КОНЦЕПЦИИ ИЗДАТЕЛЬСКОГО ПРОЕКТА «АЛТАЙ В ТРУДАХ УЧЕНЫХ И ПУТЕШЕСТВЕННИКОВ ХУІІ - НАЧАЛА ХХ ВЕКОВ» (БАРНАУЛ, 2017)}

\begin{abstract}
Аннотация. Охарактеризовано идейное ядро концепции художественного оформления издательского проекта Алтайской краевой универсальной научной библиотеки им. В. Я. Шишкова (г. Барнаул, Россия) «Алтай в трудах ученых и путешественников XVIII - начала XX веков», базовым элементом которой стали цвета и фактуры алтайских самоцветных камней. В художественном оформлении пятитомного издания также использованы репродукции малоизвестных массовому читателю живописных работ, выполненных в жанре портрета, редких акварельных пейзажных зарисовок и эскизных набросков русских и иностранных художников того периода. По замыслу редакционной группы издания, подбор иллюстративного материала должен помочь читателю проследить динамику интереса отечественных и зарубежных исследователей и путешественников к Алтаю.

Ключевые слова: книга, краеведение, алтайское краеведение, книжный дизайн, книжная иллюстрация, книжная графика, акварельный рисунок, дизайн конструктивных элементов книги, форзаиы, фронтиспис, декоративный элемент книжного издания, Алтайская краевая универсальная научная библиотека им. В. Я. Шишкова.
\end{abstract}


Современный Алтай, отдаленный от столиц на 4,5 тыс. км, известен туристам, совершившим путешествие в горы, и посетителям Государственного Эрмитажа, поражающимся искусству мастеров, которые изготовили Большую Колыванскую вазу - «царицу ваз» из зелено-волнистой яшмы.

Несколько столетий назад, в конце XVIII-XIX вв., Алтай привлекал внимание российских и зарубежных ученых своими природными богатствами, становлением и развитием горного производства. В регионе сформировался крупнейший в стране центр цветной металлургии, где выплавлялось до 90 и более процентов серебра Российского государства и находилось одно из трех камнерезных предприятий России - Колыванская шлифовальная фабрика.

С конца 1980-х гг. Алтайская краевая универсальная научная библиотека им. В. Я. Шишкова выступает активным участником краеведческого движения в регионе. Более чем за 130-летнюю историю библиотеки сформированы богатые краеведческие фонды. Опыт работы в этом направлении солидный: постоянно организуются мероприятия соответствующей тематики, 26 лет действовал клуб любителей алтайской старины, с 1987 г. и по сегодняшний день издается календарь знаменательных и памятных дат «Алтайский край»; проводятся собственные краеведческие исследования и выпускаются сборники, словари, книги и т. д. Достижения библиотеки в краеведческом направлении признаны краеведами, коллегами и научной общественностью города и края и библиотека пользуется заслуженным авторитетом и всемерной поддержкой.

В 2014 г. библиотека выступила с инициативой по подготовке к 80-летию со дня образования Алтайского края (1937) юбилейного пятитомника «Алтай в трудах ученых и путешественников XVIII - начала XX веков». Идея была поддержана, и издание вошло в план по реализации издательских проектов научно-консультативного совета по издательской политике при Губернаторе Алтайского края. Подготовка издания проходила в 2015-2016 гг., и перед составителями, уже сработавшейся на предыдущем проекте командой, стояла сложная задача: издание, представляющее Алтайский край, должно быть достойного уровня - и по содержанию, и по оформлению.

В процессе работы над пятитомником было решено: включить в него тексты исследований, посвященных Алтаю, изданные до 1917 г. и ставшие библиографической редкостью. Надо отметить, что дореволюционный Алтай охватывал огромную территорию Западной Сибири и включал в свои границы не только земли современных Алтайского края и Республики Алтай, но и большую часть нынешних Новосибирской и Кемеровской областей, южные районы Томской области и некоторые восточные районы Республики Казахстан. Составители рассчитывали на то, что издание будет представлять интерес и для жителей соседних регионов.

В сентябре 2017 г. юбилейное издание «Алтай в трудах ученых и путешественников XVIII начала XX веков» в пяти томах было издано [1-5]. В него вошли работы 36 авторов, которые размещены по хронологическому принципу, т. е. по времени обнародования работ. Предваряет каждую публикацию биографическая справка об авторе и книговедческая информация об издании или статье. Биографическую справку сопровождает портрет или, при его отсутствии, изображение титульного листа приводимого издания. После публикуемого текста дается ссылка на источник.

Хронологический отбор материала для размещения в пятитомнике позволяет проследить, как на протяжении нескольких веков менялся, трансформировался интерес иностранных и российских исследователей к Алтаю. Если в XVIII в. внимание вызывали все вопросы горнозаводского производства, то в начале XIX в. на первый план постепенно выходили этнографические исследования коренных народов Алтая и изучение торговли бийских купцов с монголами и китайцами. Во второй половине XIX в. внимание в статьях исследователей уделялось вопросам социально-экономического развития, а в начале XX в., когда регион становится центром водворения крестьян-переселенцев из Европейской России и ведущим районом развития товарного сельского хозяйства за Уралом, - этим вопросам.

Над юбилейным изданием работал коллектив составителей: научный редактор - доктор исторических наук, профессор Алтайского государственного университета Валерий Анатольевич Скубневский; сотрудники отдела редких книг Алтайской краевой библиотеки: ответственный редакторзаведующая отделом Валентина Петровна Кладова, библиотекари: Наталья Владимировна Воробьева, Светлана Николаевна Ермакова, Анастасия Дмитриевна Тетерина. Дизайн и художественное оформление осуществляла Ксения Михайловна Паршина. 
Составители ставили перед собой сложную задачу: создать одновременно и серьезное научное издание, и сборник, рассчитанный на широкую читательскую аудиторию. Чтобы разъяснить редко употребляемые, непонятные или сложные слова и тексты, был подготовлен большой объем редакторских сносок. Каждый том издания сопровождает словарь терминов (общее количество - 1210 слов), указатели: именной (общее количество - 1250 персон) и географический (общее количество - 5788 географических названий).

Солидная рукопись, общий объем которой в печатном виде составил 2636 страниц, требовала нестандартной подачи. Издание задумывалось в первую очередь как юбилейное, поэтому перед художником книги ставилась задача: художественными средствами сделать пять томов визуально «легче» и наряднее.

Идея художественной концепции издания состояла в следующем: необходимо было наглядно представить то, что отличало Алтай на протяжении XVIII-XIX веков и что возрождается в XXI веке, - камень. Художником была использована широкая палитра природных оттенков самоцветных камней: яшмы, кварциты, порфиры, азурмалахиты, белоречит и др., многие из которых добываются только на Алтае.

Имитируя природные оттенки каменной палитры Алтая, цвета крышек переплета переходят от светлого к темному. Пять томов помещены в плотный короб-футляр, в цвет последнего тома, на котором изображен герб Алтайского края и юбилейная дата, к которой и приурочен издательский проект. Отметим, что и в официальном символе региона - гербе - используются исторические символы Алтая: упомянутая выше Большая Колыванская ваза и дымящаяся доменная печь XVIII в.

Связующим элементом, расположенным на переплете каждого тома (небольшого размера) и на коробе-футляре (большой), выступает перо - тот предмет, без которого не мог обойтись ни один из авторов-путешественников при создании работы, включенной в пятитомник.

В заголовке, расположенном на корешке и верхней крышке переплета, слово «Алтай» нанесено золотым тиснением, что также отсылает к эпизоду из истории края: с 1830-х гг. Сибирь оказалась охвачена «золотой лихорадкой», а в Барнаул свозили добытое золото для переплавки.

Для оформления переплета томов были использованы редкие акварели Ивана Меркульева (1741/1748-1816), принимавшего участие в качестве художника в поисково-разведочных партиях по Алтаю, возглавляемых П. И. Шангиным в 1796 г.

Электронные копии четырех акварельных рисунков Ивана Меркульева за несколько лет до подготовки издания нашел барнаульский книжный художник А. Л. Кальмуцкий и передал в отдел редких книг библиотеки. Это «Вид озера Колывана с юго-западной стороны» (XVIII в.), «Колыван-озеро с юго-западной стороны» (XVIII в.), «Вид Коргонской каменоломни» (XVIII в.), «Вид озера Колывана с южной стороны» (XVIII в.). Для одного из томов использована гравюра «Вид берегов реки Коргона» (XVIII в.) из альбома Г. Е. Щуровского - исследователя, побывавшего на Алтае в 1844 г.

Для форзацев, каждого из пяти томом была выполнена неизобразительная композиция, похожая одновременно и на камень, и на старинную «мраморную» бумагу. Причем цвета форзаца как бы продолжают и поддерживают цвет переплета.

Художник издания подготовил набор изящных округлых буквиц, имитирующих буквы, написанные пером, что возвращает читателя во времена, когда авторы только таким инструментом писали свои статьи (рис. 1).

Каждый том начинается с фронтисписа - рисунка, выполненного пером и тушью, раскрывающего суть содержания тома. На каждом из рисунков приводятся цитаты из работ исследователей, приведенные в предисловии к данному тому. Причем шрифт, используемый для цитат на рисунках, отличается от округлых заглавных букв, используемых в тексте издания. Этот шрифт больше похож на резкий почерк писцов сибирских летописей XVI-XVII вв.

На рисунке к первому тому изображены природные просторы далекого края: холмы, виднеющиеся вдалеке горы и высокое небо - то, что видели своими глазами путешественники (рис. 2). В этом томе собраны тексты работ известных ученых XVIII в., исследовавших вопросы горнозаводского производства; в этих текстах нашло отражение восхищение участников экспедиций природой Алтая [1].

Во второй том включены работы российских и зарубежных ученых и публицистов начала XIX в., исследующих вопросы геологического строения Алтайских гор, рудных богатств, истории 
горного производства, вопросы этнографии коренных народов Алтая, торговли местных купцов с монголами и китайцами [2]. На рисунке к тому видны и сторожевая башня, с которой начиналось освоение Сибирского региона, и знакомые силуэты крыш зданий старого Барнаула, возница, сидящий в груженой телеге, запряженной лошадью, который, вероятно, отправляется в дорогу (рис. 3).

В третий том, посвященный вопросам социально-экономического развития Алтая, вошли работы исследователей второй половины XIX в [3]. На рисунке видны силуэты гор, склоны холмов и восходящее солнце, что отражает надежду на дальнейшее развитие богатейшего региона, поскольку в этот период происходил упадок горной промышленности (рис. 4). Исследователи Алтая, работы которых собраны в этом томе, приходят к выводу о больших перспективах в дальнейшем развитии Алтая и предлагают конкретные пути к решению имеющихся проблем.

В четвертый том полностью вошел сборник «Алтай: историко-статистический сборник по вопросам экономического и гражданского развития Алтайского горного округа», изданный в 1890 г. под редакцией П. А. Голубева [4]. На рисунке мы видим перо, уже использованное на переплете томов, и стопку бумаг - так художник увидел результаты работы настоящего энтузиаста, составителя и редактора сборника, который смог объединить и увлечь группу единомышленников и в короткое время подготовить книгу, энциклопедического характера, востребованную и у современных исследователей (рис. 5).

В пятом томе размещены работы авторов рубежа XIX-XX вв. - периода, когда Алтай становится одним из главных в Сибири районов водворения крестьян-переселенцев из Европейской России и ведущим районом развития товарного сельского хозяйства [5]. На рисунке- оставленное автором рабочее место под мягким светом лампы, с очками, лежащими на столе (рис. 6). Это - рабочее место сибирского интеллигента, часто ссыльного народника, отдавшего много сил делу изучения Алтая.

Для всего издания была разработана колонлинейка с декоративным элементом, выполненным в растительном стиле. Для каждого из пяти томов подготовлен декоративный элемент, своеобразная «концовка», размещенная по окончанию глав текста (рис. 7).

К биографической статье каждого из авторов были подобраны портреты, причем составители постарались найти не использованные ранее в краеведческих изданиях. В нескольких статьях помещены приведенные в оригиналах иллюстрации. Использование иллюстративного ряда позволило также сделать большое по объему и серьезное по содержанию издание более легким и изящным.

Тиражированием издания занимался коллектив ОАО «Алтайский дом печати» (г. Барнаул). Полиграфисты ответственно и творчески подошли к работе над изданием, поэтому замыслы художника были реализованы. Благодаря слаженной работе всех участников издательского проекта юбилейное издание «Алтай в трудах ученых и путешественников XVIII - начала XX веков» отличает гармоничное соединение классических основ оформления книги с современными дизайнерскими и техническими решениями.

Издательский проект библиотеки был оценен профессиональным сообществом. В марте 2018 г. признан победителем краевого конкурса «Лучшая книга Алтая - 2017» в номинации «Лучшее научное издание». В сентябре 2018 г. на открытом межрегиональном конкурсе «Книга года: Сибирь Евразия - 2018» пятитомное издание «Алтай в трудах ученых и путешественников XVIII - начала XX веков» стало лауреатом конкурса в номинации «Лучшая краеведческая книга». В 2019 г. получен диплом победителя VIII Сибирского межрегионального конкурса «Университетская книга - 2019. Евразийский мир: наука, образование, культура» (с международным участием (Россия, Монголия).

Тираж издания составил 2500 экземпляров. Большая его часть распределена в краевые и муниципальные библиотеки, краевые музеи и библиотеки краевых образовательных организаций и др., оставшаяся часть поступила в свободную продажу. Это юбилейное издание с тщательно отобранными для публикации работами дореволюционных авторов, прекрасно оформленное и изданное на высоком полиграфическом уровне, предназначено для самой широкой читательской аудитории. Нужную информацию найдут для себя как школьники, начинающие изучать историю своей малой родины, так и краеведы, которые откроют для себя новые факты или не известного им ранее автора; как студенты, ученые, специалисты в области истории, географии, геологии, биологии, филологии, так и жители, и гости Алтая. 


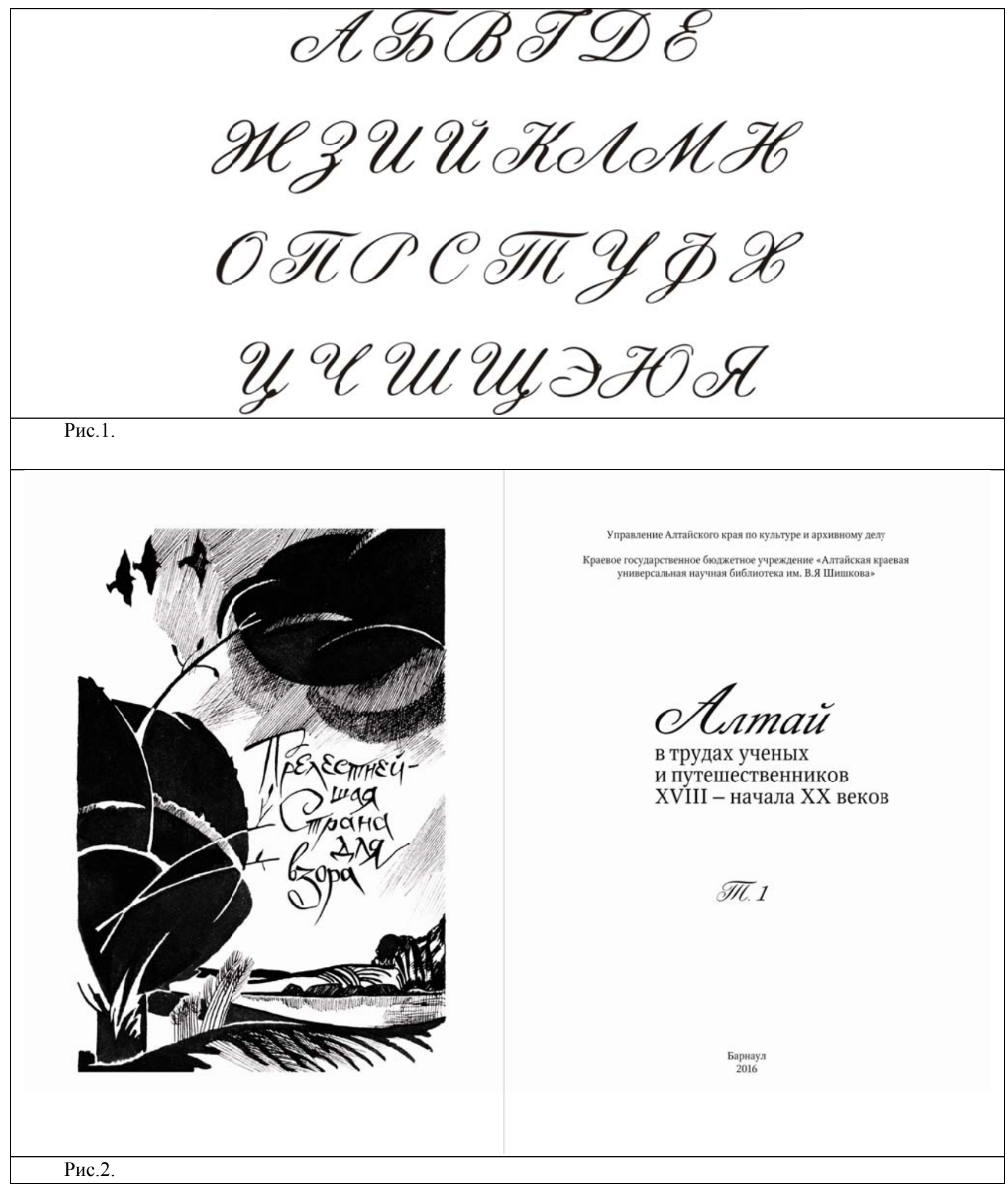



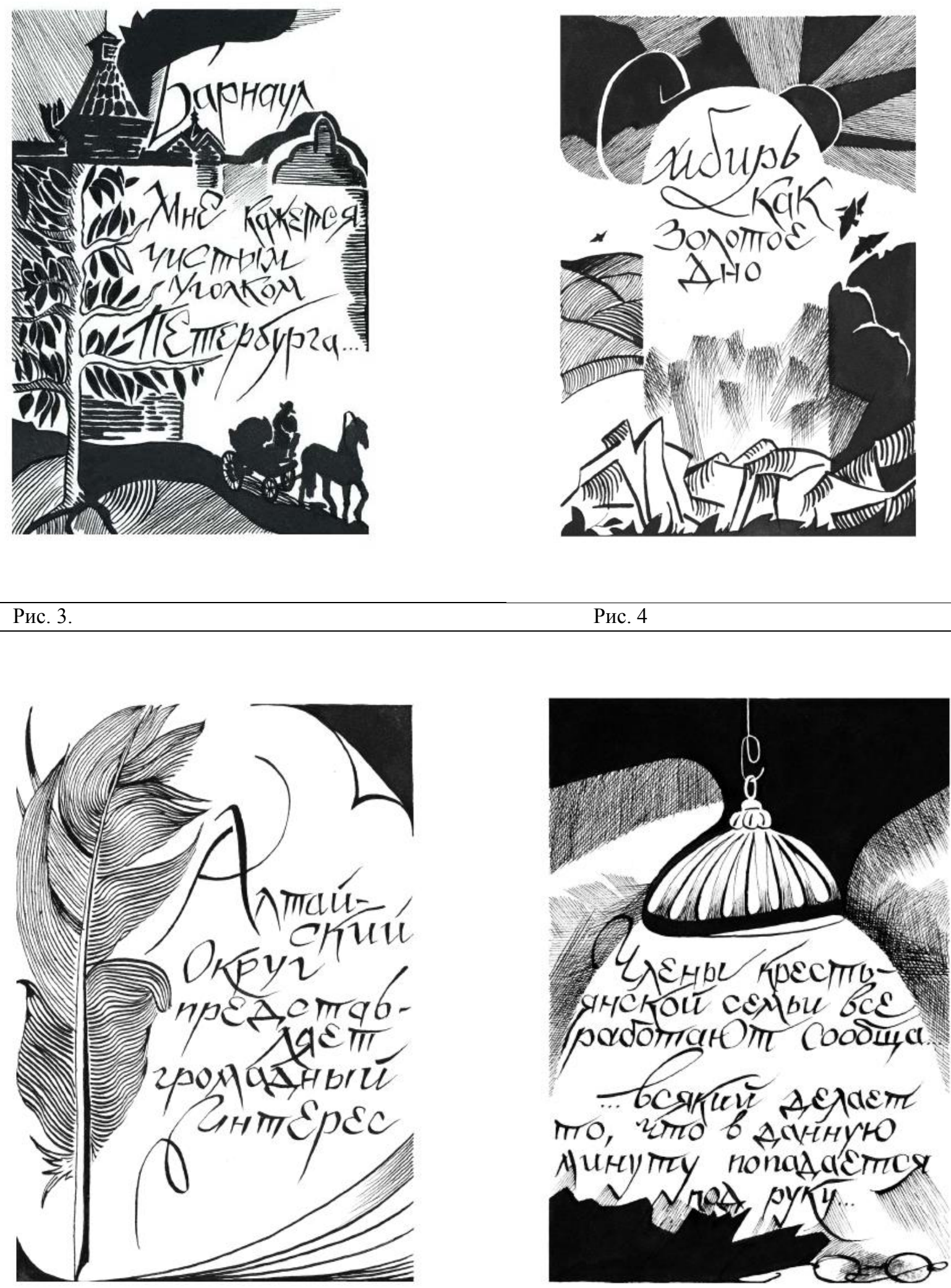


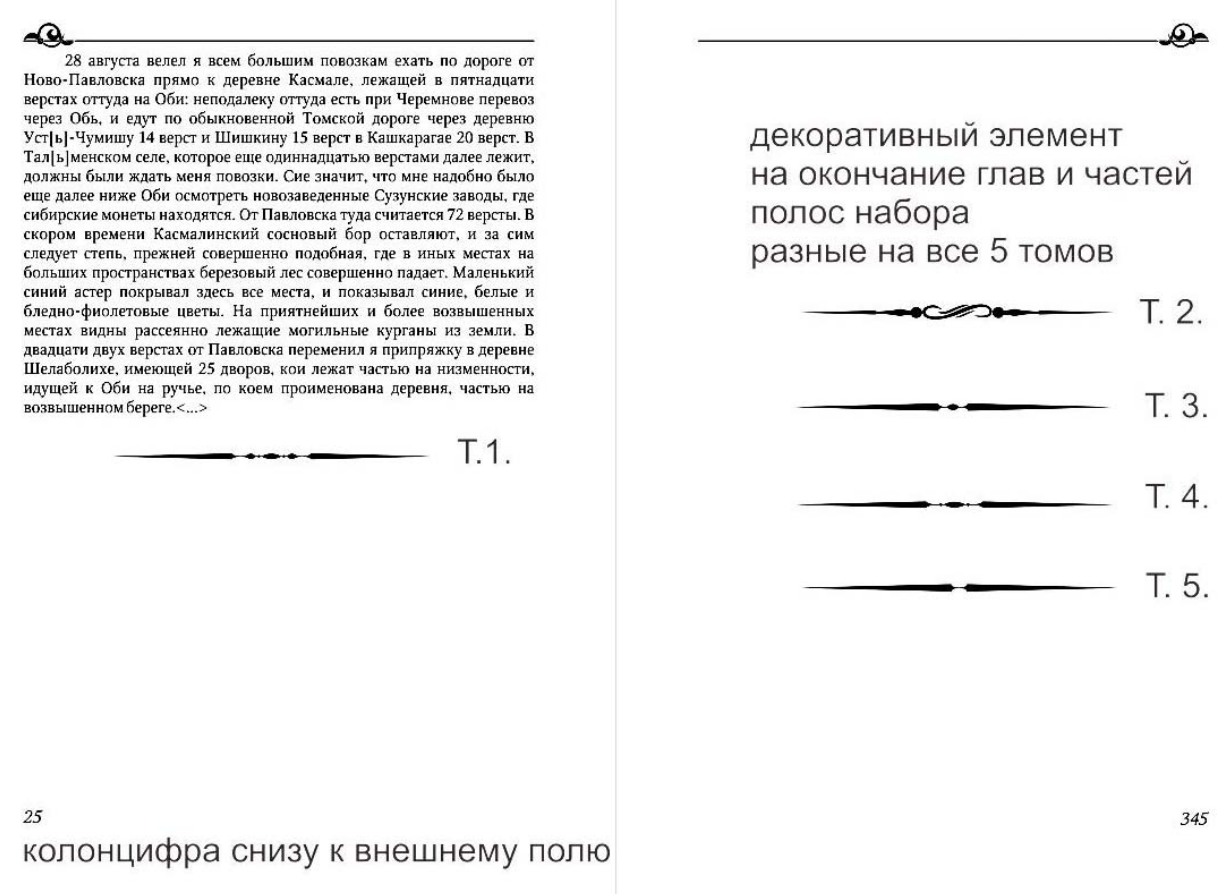

\section{Список литературы}

1. Алтай в трудах ученых и путешественников XVIII - начала XX веков : [в 5 т.] / [сост. : В. А. Скубневский [и др.] ; редкол. : В. П. Кладова (отв. ред.) [и др.]. - Барнаул : АКУНБ, 2017. - Т. 1. - 419 с. : ил., портр.

2. Алтай в трудах ученых и путешественников XVIII - начала XX веков : [в 5 т.] / [сост. : В. А. Скубневский [и др.] ; редкол. : В. П. Кладова (отв. ред.) [и др.]. - Барнаул : АКУНБ, 2017. - Т. 2. - 494 с. : ил., портр.

3. Алтай в трудах ученых и путешественников XVIII - начала XX веков : [в 5 т.] / [сост. : В. А. Скубневский [и др.] ; редкол. : В. П. Кладова (отв. ред.) [и др.]. - Барнаул : АКУНБ, 2017. - Т. 3. - 558 с. : ил., портр.

4. Алтай в трудах ученых и путешественников XVIII - начала XX веков : [в 5 т.] / [сост. : В. А. Скубневский [и др.] ; редкол. : В. П. Кладова (отв. ред.) [и др.]. - Барнаул : АКУНБ, 2017. - Т. 4. - 542 с. : ил., портр., табл.

5. Алтай в трудах ученых и путешественников XVIII - начала XX веков : [в 5 т.] / [сост. : В. А. Скубневский [и др.] ; редкол. : В. П. Кладова (отв. ред.) [и др.]. - Барнаул : АКУНБ, 2017. - Т. 5. - 623 с. : ил., портр.

Natalia $\boldsymbol{V}$. Vorobyova

Shishkov Altai Regional Universal Scientific Library (Barnaul, Russia) ork_akunb@mail.ru

\section{ALTAI STONE PALETTE IN “ALTAI IN THE WORKS OF SCIENTISTS AND TRAVEL-} ERS, THE $18^{\text {TH }}$ - THE BEGINNING OF THE $20^{\text {TH }}$ CENTURY” PUBLICATION PROJECT DESIGN (BARNAUL, RUSSIA; 2017)

Abstract. The article describes thought core of design made for publication project "Altai in the Works of Scientists and Travelers, the $18^{\text {th }}$ the Beginning of the $20^{\text {th }}$ Century" by Shishkov Altai Regional Universal Scientific Library (Barnaul, Russia), the basic element of which became colors and surface type of the Altaian semiprecious stones. Reproduction of little known pictural works made in portrait genre, rare landscape water-colors, esquisses by Russian and foreign painters lived around this time are also used in artistic design of five-volume issue. On the issue's editorial board's idea, selection of illustrations should help to a reader to trace a dynamics of interests took by domestic and foreign researchers and travelers in Altai.

Keywords: a book, local history, Altai local history, design of a book, book illustration, book pictures, water-color, design of structural components of a book, book end-leafs, book frontispieces, a picturesque element of a book, Shishkov Altai Regional Universal Scientific Library. 